\title{
A Full-Blown Case of Bronchiectasis: Kartagener Syndrome Without Infertility Diagnosed Later in Life
}

\author{
Madeeha Subhan $^{1}$, Waleed Sadiq ${ }^{2}$ \\ 1. Capital Hospital Islamabad, Ayub Teaching Hospital, Abbottabad 2. Department of Medicine, Shifa \\ International Hospital
}

$\square$ Corresponding author: Madeeha Subhan, madeehas99@gmail.com

Disclosures can be found in Additional Information at the end of the article

\section{Abstract}

Kartagener syndrome (KS) is a rare autosomal recessive genetic ciliary disorder characterized by situs inversus, chronic sinusitis, bronchiectasis, and infertility. KS is associated with ultrastructural anomalies of the cilia in epithelial cells covering the upper and lower respiratory tracts and spermatozoa flagella. This case describes a patient with KS with situs inversus and sudden onset bronchiectasis with a sharp decline in respiratory function presenting later in life but without sinusitis or infertility.

Categories: Genetics, Internal Medicine, Pulmonology

Keywords: kartagener syndrome, infertility, bronchiectasis

\section{Introduction}

Kartagener syndrome (KS), also known as immotile cilia syndrome, is an autosomal recessive condition that results from a defect in the dynein arm. The immotile cilia seen in KS is due to defects in the ultrastructural organization of the cilia [1-3]. KS presents with the classic symptoms of situs inversus, bronchiectasis, and polyposis nasi.

\section{Case Presentation}

A 59-year-old man presented to the emergency department after a road traffic injury in which he was a restrained driver. Trauma protocol was applied, and he was investigated for any injuries or bleeding. He had mild bruises on his chest, but there were no other notable findings from the physical examination. A chest x-ray revealed situs inversus with no rib fractures. Due to this incidental finding, he was asked about any other systemic symptoms. The patient then reported having a fever and cough for the past two months for which he took over the counter medications (which did not help those symptoms). The fever was low grade, gradual in onset, remitting in nature with peaks in the evening, and was occasionally associated with rigors and chills. He also had a cough that was productive with whitish sputum. Sputum production gradually increased from less than half a teaspoon to about two teaspoons. After review, we found no systemic concerns. The patient was troubled since he leads an active life with no comorbidities. The patient is married, has three children, does not smoke, and is not an alcoholic. His family history was positive for diabetes mellitus. On examination, his central nervous system was intact. Heart sounds were normal with the point of maximal impulse auscultated on the right side of the chest. On respiratory exam, he had bilateral expiratory rhonchi and bilateral lower lobe inspiratory crepitus. The patient's bowel sounds were positive, and we noted right hypochondriac fullness with no visceromegaly. His blood pressure was 


\section{Cureus}

120/80 mmHg, pulse was 89 beats per minute, and his respiratory rate was 20 breaths per minute. On pulmonary function tests, his forced expiratory volume after one second was $50 \%$. During hospital admission, he was given moxifloxacin, and he subsequently improved.

The patient's complete blood picture and metabolic profile are shown in Tables 1-2.

\section{Hemoglobin}

White blood cells

Red blood cells

Platelets

Mean corpuscular volume.
$6.21 \mathrm{mmol} / \mathrm{L}$

$25.3 \times 109 / L$

$5.6 \times 1012 / L$

$127.7 \times 109 / L$

$84.4 \mathrm{fL}$

\section{TABLE 1: Complete blood picture}

\section{Sodium}

Potassium

Chloride

Urea nitrogen

Creatinine

Glucose

Alanine aminotransferase

Alkaline phosphatase

Total bilirubin
$136 \mathrm{mmol} / \mathrm{L}$

$4.4 \mathrm{mmol} / \mathrm{L}$

$103 \mathrm{mmol} / \mathrm{L}$

$1.9 \mathrm{mmol} / \mathrm{L}$

$79.56 \mu \mathrm{mol} / \mathrm{L}$

$6.99 \mathrm{mmol} / \mathrm{L}$

$0.433 \mu \mathrm{kat} / \mathrm{L}$

$6.78 \mu \mathrm{kat} / \mathrm{L}$

$10.26 \mu \mathrm{mol} / \mathrm{L}$

\section{TABLE 2: Complete metabolic profile}

On evaluating the patient's chest x-ray, we noted mild fibrotic changes in both lung fields. We also noted air trapping and flattening of both hemidiaphragms. We also noted increased bronchovascular marking. Cardiac shadow was slightly enlarged with a cardiothoracic ratio of $14 / 26 \mathrm{~cm}$. The patient had mild cardiomegaly with pulmonary congestion as shown in Figure 1. 


\section{Cureus}

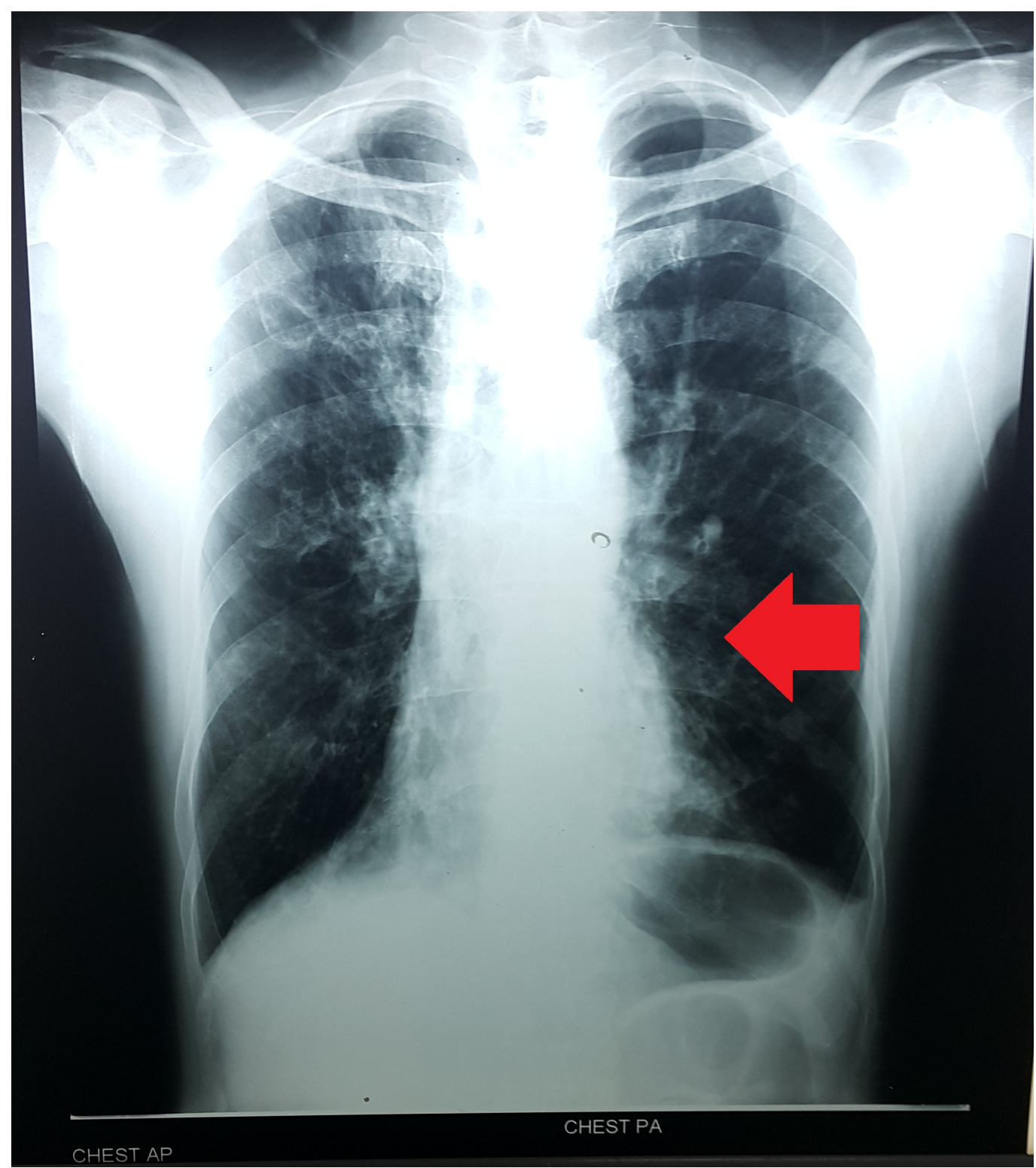

\section{FIGURE 1: Chest x-ray showing mild cardiomegaly with pulmonary congestion and dextrocardia}

The patient underwent a high-resolution computed tomography (CT) scan. We noted mild bilateral apical scarring, bronchiectasis involving both lungs primarily in the right lower and left upper lobes, a mirror image configuration with abdominal situs inversus and dextrocardia. The patient had multiple subcentimeter to borderline benign-looking calcified lymph nodes in the paratracheal, subcarinal, precarinal, preaortic, and bilateral aortopulmonary locations. We noted mild atherosclerotic calcification in the coronary arteries and diffuse generalized osteopenia due to senile osteoporosis.

We diagnosed the patient with KS with active bronchiectasis as shown in Figure 2. 


\section{Cureus}

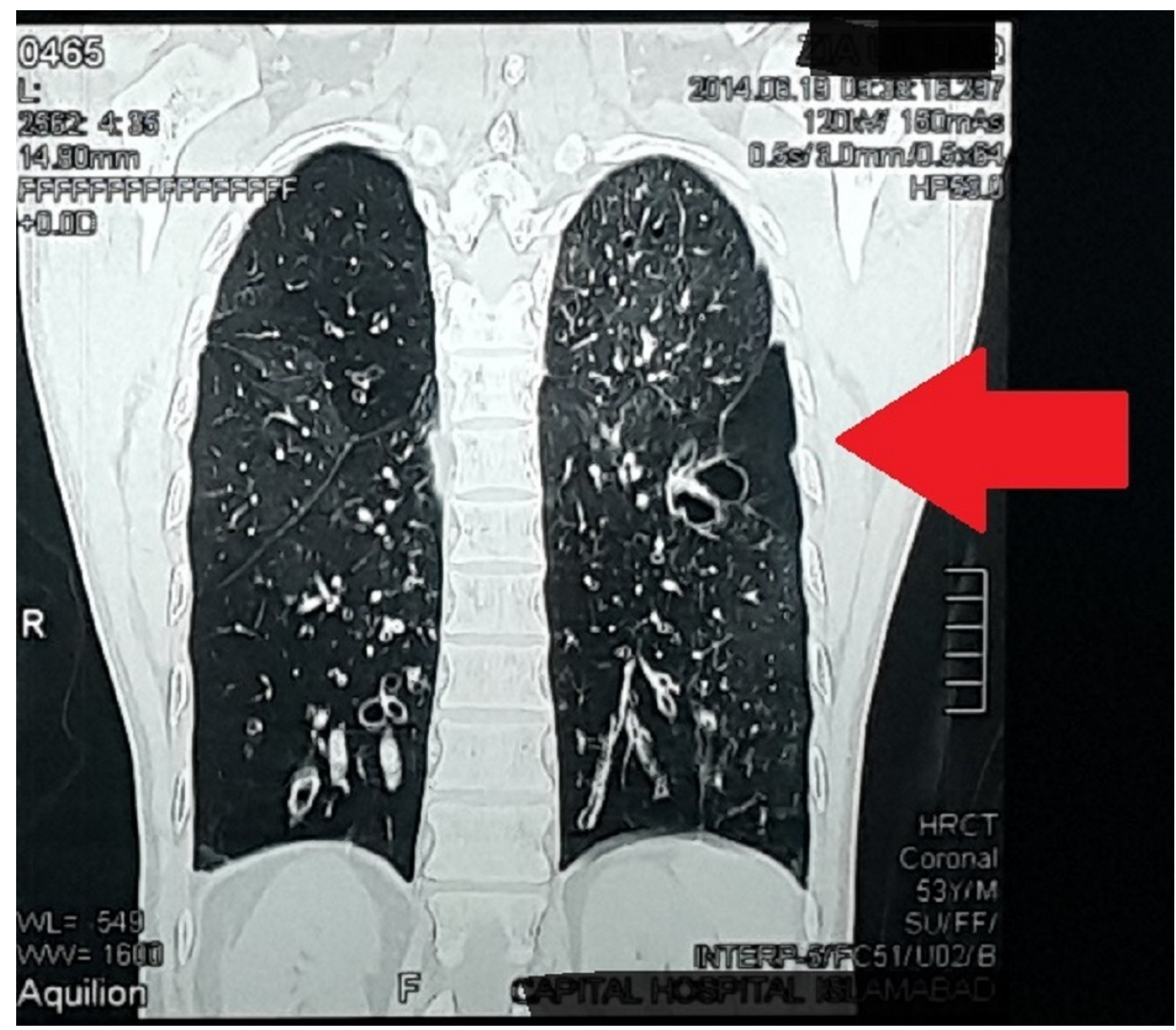

FIGURE 2: Computed tomography scan showing bronchiectasis

\section{Discussion}

KS is a part of primary ciliary dyskinesia occurring in approximately one in 30,000 people [4], but it may range from one in 12,500 to one in 50,000 [5]. Diagnostic criteria are recurrent chest infections, bronchitis, rhinitis since childhood, along with any of the following: situs inversus in the patient or a sibling, alive but immotile spermatozoa, reduced or absent transbronchial mucociliary clearance, and cilia showing characteristic ultrastructural defects [6]. The severity of symptoms is quite variable, although the symptoms are present from birth [7-8]. Our patient presented at age 59, and he was previously healthy with normal fertility and three children. Male patients with KS invariably present with infertility while women have reduced fertility [9]. Infertility in male KS patients is due to diminished sperm motility, and in females, it is due to defective ovum transport [10]. Given our patient's age and fertility, it is possible that those with KS can have normal fertility and be diagnosed later in life.

\section{Conclusions}

The benefits of early KS diagnosis have yet to be confirmed, but it is likely that an early diagnosis will aid in preserving pulmonary function, quality of life, and life expectancy. However, large prospective studies are needed to validate this theory. KS patients frequently have repeated sinopulmonary infection episodes, for which they have to seek medical attention; this is largely the reason for their morbidity. However, infertility is also an important aspect that needs to be addressed so that they may be offered a suitable option that could help them 
have children if desired. Moreover, it is important to note that KS patients may present later in life with full-blown bronchiectasis and a sharp decline in pulmonary functions as illustrated in this case.

\section{Additional Information \\ Disclosures}

Human subjects: Consent was obtained by all participants in this study. Conflicts of interest: In compliance with the ICMJE uniform disclosure form, all authors declare the following:

Payment/services info: All authors have declared that no financial support was received from any organization for the submitted work. Financial relationships: All authors have declared that they have no financial relationships at present or within the previous three years with any organizations that might have an interest in the submitted work. Other relationships: All authors have declared that there are no other relationships or activities that could appear to have influenced the submitted work.

\section{References}

1. Afzelius BA: A human syndrome caused by immotile cilia . Science. 1976, 193:317-319. 10.1126/science. 1084576

2. Eliasson R, Mossberg B, Camner P, Afzelius BA: The immotile-cilia syndrome. A congenital ciliary abnormality as an etiologic factor in chronic airway infections and male sterility. $\mathrm{N}$ Engl J Med. 1977, 297:1-6. 10.1056/NEJM197707072970101

3. Pedersen H, Mygind N: Absence of axonemal arms in nasal mucosa cilia in Kartagener's syndrome. Nature. 1976, 5:494-5. 10.1038/262494a0

4. Season D: Bronchiectasis. Crofton and Douglas's Respiratory Diseases, Fifth Edition. Seaton A, Seaton D, Leitch G (ed): Blackwell Science, Hoboken, US; 2004. 794-828. 10.1002/9780470695999

5. Barthwal MS: Kartagener's syndrome in a fertile male - An uncommon variant . Lung India. 2006, 23:123-510. 10.4103/0970-2113.44404

6. Eliason R, Mossberg B, Camner P, Afzelius BA: The immotile cilia syndrome: A congenital ciliary abnormality as an etiologic factor in chronic airway infection and male sterility. N Engl J Med. 1977, 297:1-6. 10.1056/NEJM197707072970101

7. Kordus RJ, Price RL, Davis JM, Whitman-Elia GF: Successful twin birth following blastocyst culture of embryos derived from the immotile ejaculated spermatozoa from a patient with primary ciliary dyskinesia: A case report. J Assist Reprod Genet. 2008, 25:437-43. 10.1007/s10815-008-9254-X

8. Coren ME, Meeks M, Morrison I, Buchdahl RM, Bush A: Primary ciliary dyskinesia: Age at diagnosis and symptom history. Acta Paediatr. 2002, 91:667-9. 10.1111/j.16512227.2002.tb03299.x

9. Morillas HN, Zariwala M, Knowles MR: Genetic causes of bronchiectasis: primary ciliary dyskinesia. Respiration. 2007, 74:252-63. 10.1159/000101783

10. Knowles MR, Daniels LA, Davis SD, et al.: Primary ciliary dyskinesia. Recent advances in diagnostics, genetics, and characterization of clinical disease. Am J Respir Crit Care Med. 2013, 188:913. 10.1164/rccm.201301-0059CI 